\title{
Semeadura direta na produção do milho em agricultura de sequeiro na região Nordeste do Brasil
}

\author{
No-tillage on corn production in rainfed agriculture in Northeast Brazil
}

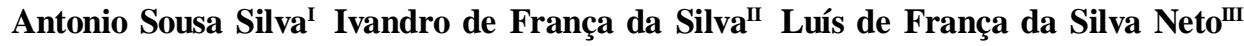 \\ Cícero de Souza $^{\mathrm{IV}}$
}

RESUMO

Quando implantado de modo eficiente, a semeadura direta beneficia o solo e as culturas. No Brasil, a maioria dos estudos com plantio direto concentra-se no Sul e no Centro-Oeste, carecendo de informações sobre esse sistema de manejo do solo no ambiente da região Nordeste. O objetivo deste trabalho foi avaliar a influência da semeadura direta na produtividade do milho em agricultura de sequeiro na região Nordeste do Brasil, em um experimento conduzido em Alagoinha-PB durante sete anos. As culturas do milho (Zea mays) e do guandu (Cajanus cajan) foram implantadas em três sistemas de manejo: milho em cultivo convencional (CC), milho em semeadura direta (SD), milho em semeadura direta com guandu intercalar $(S G)$, na presença e ausência de adubação com N, P e K. As amostras de solo foram coletadas no início e no final do experimento, sendo determinados a densidade do solo e de partículas, a porosidade total, o diâmetro médio ponderado de agregados secos e úmidos e o indice de estabilidade de agregados. Também foram quantificadas a percentagem de cobertura do solo e a produtividade de grãos de milho. A porosidade do solo e a estabilidade de agregados foram menores após o período avaliado. A cobertura do solo aumentou significativamente, chegando a cobrir $96 \%$ da área nos sistemas $S D$ e $S G$, no início do desenvolvimento da cultura. A adubação e os sistemas $S D$ e $S G$ influenciaram positivamente na produtividade do milho. A precipitação pluvial foi o fator que causou maior variabilidade nos resultados ao longo do estudo.

Palavras-chave: cobertura do solo, sistemas de manejo do solo, plantio direto, preparo convencional.

\begin{abstract}
When efficiently introduced, no-tillage system benefices soil and crops. In Brazil, no-tillage studies are concentrated in South and Center-west regions, being necessary information about it in Northeast region. The aim of this study was to evaluate the no-tillage influence on maize yield under rainfed agriculture in Northeast Brazil, in an experiment conducted during seven years. The crops of maize (Zea mays) and pigeon pea (Cajanus cajan) were used in three soil management systems: maize in conventional tillage $(C C)$, maize in no-tillage (SD), maize in no-tillage plus pigeon pea sowed in the interrow $(S G)$, with presence and absence of mineral $N$, $P$ and $K$ fertilization. Soil samples were collected at the beginning and the end of the experiment to determine soil bulk density, soil particle density, total porosity, dry and wet mean weight aggregate diameters and aggregate stability index. It was also quantified soil cover rate and maize yield. The soil porosity and aggregate stability were lower after the study period. Soil coverage increased significantly, about $96 \%$ of the area under $S D$ and $S G$ systems, early in the culture development. Mineral fertilization and no-tillage systems highly influenced the maize yield. The rainfall was the factor that caused greater variability on the results of this study.
\end{abstract}

Key words: soil cover, soil management systems, no tillage, conventional tillage.

\section{INTRODUÇÃO}

O uso do sistema de plantio direto (SPD) se iniciou no Sul do Brasil no final da década de 1970 e se

Instituto Federal Baiano, Campus Senhor do Bonfim, Rua José Tomaz Filho, 25, 58398-000, Remígio, PB, Brasil. E-mail: sousaaantonio@bol.com.br. Autor para correspondência.

IIDepartamento de Solos e Engenharia Rural (DSER), Centro de Ciências Agrárias (CCA), Universidade Federal da Paraíba (UFPB), Areia, PB, Brasil.

IIIEmbrapa Solos, Rio de Janeiro, RJ, Brasil.

${ }^{\mathrm{IV}}$ Emater, Nova Mamoré, RO, Brasil. 
estendeu até a região Centro-Oeste a partir da década de 1990 (TORRES, 2003), tendo como principal objetivo proteger o solo contra a erosão. Porém, ao longo desse período, as pesquisas passaram a enfocar as alterações físicas, químicas e biológicas do solo, decorrentes da semeadura direta (VIEIRA et al., 1991; BAYER et al., 2000; AMARAL et. al., 2008). Um dos fundamentos do SPD é a manutenção de quantidade significativa de palha na superfície do solo, o que é conseguido através de sequências planejadas de culturas, definidas em função dos sistemas de produção e das condições edafoclimáticas regionais. Na região Centro-Oeste, por exemplo, a braquiária se apresentou como a melhor alternativa para cobertura do solo e produção de palha na entressafra das culturas comerciais (ANDRIOLI, 2004; TORRES, 2003).

A forma de agricultura predominante no Nordeste é de subsistência, praticada em pequenas propriedades rurais nas condições de sequeiro, em que a produtividade depende da fertilidade natural dos solos (SAMPAIO et al., 1995). Nessas condições, os solos se apresentam erodidos, pobres em nutrientes e com níveis baixos de matéria orgânica. FRAGA (2002) observou que esse tipo de exploração diminuiu o estoque de carbono e de nitrogênio do solo. Assim, existem dificuldades de implantação da semeadura direta na região Nordeste devido ao pequeno acúmulo de cobertura morta, uma vez que não há condições climáticas para se estabelecer uma sucessão de culturas ao longo do ano, em função de que o período chuvoso é curto no ano. Outro fator é a temperatura elevada da região, que acelera a decomposição dos resíduos, diminuindo rapidamente a cobertura do solo após a colheita das culturas (SILVA NETO, 2003; NUNES et al., 2004). Após quatro anos de pesquisa na região Nordeste, SILVA (2002) conseguiu acumular cobertura morta em área cultivada com a cultura do milho sob semeadura direta. Entretanto, esses resíduos foram decompostos rapidamente e não foram suficientes para aumentar a produtividade em relação ao sistema convencional de cultivo nas safras subsequentes.

Por isso, há necessidade de se aprofundar as pesquisas com semeadura direta na região Nordeste, levando-se em consideração as condições climáticas que são variáveis dentro da região. Para acumular fitomassa em regiões com déficit hídrico em boa parte do ano, devem-se semear culturas de sucessão intercalar à cultura principal quando esta estiver estabelecida, para viabilizar o seu crescimento inicial no período no qual ainda há água disponível no solo e, assim, aumentar a produção de fitomassa para cobertura do solo no período seco. Outra alternativa é semeadura de culturas que possuam alta relação $\mathrm{C} / \mathrm{N}$ na fitomassa, característica que diminui a taxa de decomposição em função da maior recalcitrância química da matéria orgânica, que permanece protegendo o solo por mais tempo (SILVA, 2002; SILVA NETO, 2003; NUNES et al., 2004; NUNES, 2006).

O objetivo deste estudo foi avaliar o acréscimo de cobertura do solo ao longo dos anos nos sistemas implantados e analisar os efeitos da semeadura direta nas propriedades físicas do solo e na produtividade da cultura do milho em comparação com o sistema convencional.

\section{MATERIAL E MÉTODOS}

O experimento foi conduzido entre os anos de 1998 a 2004 na Estação Experimental da Empresa Estadual de Pesquisa Agropecuária da Paraíba (EMEPA-PB), situada no município de Alagoinha, com clima do tipo As', de acordo com a classificação de Köppen (BRASIL, 1972), que se caracteriza por ser quente e úmido, com chuvas no período de março a setembro. O solo do local é classificado como LUVISSOLO CRÔMICO Pálico abrúptico (EMBRAPA, 2006), com textura Franco Arenosa $\left(550 \mathrm{~g} \mathrm{~kg}^{-1}\right.$ de areia, $270 \mathrm{~g} \mathrm{~kg}^{-1}$ de silte e $180 \mathrm{~g} \mathrm{~kg}^{-1}$ de argila). Antes da implantação dos sistemas, a área foi explorada com rotação de culturas de milho, mandioca, gergelim, feijão e cana de açúcar durante 10 anos. A análise química do solo da área, antes da instalação da pesquisa, apresentava as seguintes características: 0,062; 0,$001 ; 0,177 ; 2,86$ e $1,66 \mathrm{cmol}_{\mathrm{c}} \mathrm{dm}^{-3}$ para Na, Al, K, Ca e $\mathrm{Mg}$ respectivamente, $5,08 \mathrm{mg} \mathrm{dm}^{-3}$ para $\mathrm{P}, 9,89 \mathrm{~g} \mathrm{dm}^{-3}$ para matéria orgânica e $\mathrm{pH}$ de 5,31.

Para implantação do experimento, toda a área foi preparada com tração mecânica, com uma aração e duas gradagens. Foram usados três sistemas de manejo do solo, na presença e ausência de adubação mineral com N, P e K em delineamento experimental de blocos ao acaso, com três repetições, em parcelas experimentais de $5 \times 5 \mathrm{~m}$.

Os três sistemas de manejo de solo foram: semeadura direta do milho, consorciado com guandu (SG), semeadura direta do milho solteiro (SD) e semeadura de milho solteiro em cultivo convencional (CC). No sistema CC, utilizou-se capina manual e os resíduos culturais foram queimados e as cinzas incorporadas ao solo através de revolvimento com enxada. O SD se caracterizou pelo não revolvimento do solo, a manutenção dos resíduos culturais e o uso de herbicidas. O sistema SG incluiu, além das operações realizadas no SD, o plantio de fileiras duplas de guandu nas extremidades da parcela, que eram cortados a $25 \mathrm{~cm}$ de altura e sua fitomassa usada como cobertura de 
solo por ocasião da semeadura, no início de cada safra. O milho, cultivar 'BR 106', foi semeado em covas feitas manualmente com auxílio de enxada, no espaçamento de $1,00 \mathrm{~m}$ entre fileiras e $0,20 \mathrm{~m}$ entre covas, com uma população final de 50 mil plantas ha-1 ${ }^{-1}$ A adubação foi realizada com base na análise de solo, com aplicação de $90 \mathrm{~kg}$ de nitrogênio na forma de sulfato de amônio, $80 \mathrm{~kg}$ de fósforo na forma de superfosfato simples e $45 \mathrm{~kg}$ de potássio na forma de cloreto de potássio. A aplicação do nitrogênio foi parcelada, sendo $1 / 3$ por ocasião da semeadura, junto com o fósforo e o potássio, e os 2/3 restantes em cobertura, 30 dias após a aplicação anterior.

Para as análises físicas, foram coletadas amostras indeformadas de solo na camada de $0,0 \mathrm{a} 0,2 \mathrm{~m}$ de profundidade, sendo a primeira coleta na implantação do experimento e a última após sete anos de cultivo. A separação dos agregados e o diâmetro médio ponderado por via seca (DMPAs) foi realizada utilizando-se amostras com $50 \mathrm{~g}$ de agregados com diâmetro inferior a $9,52 \mathrm{~mm}$, passadas em peneiras de 2,$00 ; 1,00 ; 0,50 ; 0,25 ; 0,106$ e $0,053 \mathrm{~mm}$ de malha com auxílio de um vibrador Produtest, durante um minuto, como descrito por SILVA \& MIELNICZUK (1997). A separação dos agregados e a determinação do diâmetro médio ponderado por via úmida (DMPAu) seguiu a metodologia de TISDALL et al. (1978), modificado por CARPENEDO \& MIELNICZUK (1990). O índice de estabilidade em água das unidades estruturais do solo foi obtido através da relação entre o diâmetro médio ponderado dos agregados úmidos e o diâmetro médio ponderado dos agregados secos (DMPAu/DMPAs), conforme SILVA \& MIELNICZUK (1997). Adensidade do solo, de partículas e a porosidade total foram determinadas conforme EMBRAPA (1997).
A percentagem de cobertura foi determinada no início do desenvolvimento da cultura utilizando-se o método de transecção linear (SLONEKER \& MOLDENHAUER, 1977) e a precipitação pluvial foi medida por meio de um pluviômetro instalado próximo à área do ensaio. A produtividade de grãos de milho foi determinada através da coleta de todas as espigas da área útil da parcela, correspondente a $12,0 \mathrm{~m}^{2}$, e correção da umidade para $12 \%$ com resultados expressos em $\mathrm{Mg} \mathrm{ha}^{-1}$.

A análise estatística foi efetuada considerando-se parcelas subdivididas no tempo e, quando observada diferença significativa pelo teste $\mathrm{F}$, as médias foram comparadas pelo teste de Tukey a $5 \%$ de probabilidade de erro.

\section{RESULTADOS E DISCUSSÃO}

A densidade de partículas permaneceu a mesma em todos os tratamentos, ou seja, ela não foi influenciada pela adubação, sistemas de manejo ou anos de cultivo (Tabela 1). Isto ocorre porque a fração sólida mineral está mais ligada à gênese do solo do que ao seu manejo.

A densidade do solo não foi influenciada pelos sistemas de manejo (Tabela 1), provavelmente porque não houve tráfego de máquinas e implementos na área e a capina manual promove apenas escarificação superficial do solo. Esses dados concordam com os obtidos por CARNEIRO et al. (2009), mas discordam dos de BERTOL et al. (2000), que observaram valores de densidade do solo $12 \%$ maior na semeadura direta do que no cultivo convencional com aração e gradagem, cuja diferença foi atribuída às operações de manejo e à reconsolidação natural do solo devido à ausência de

Tabela 1 - Densidade de partículas e do solo, porosidade total, diâmetro médio ponderado de agregado em base seca (DMPAs) e úmida (DMPAu) e relação DMPAs/DMPAu do solo, em três sistemas de manejo do solo, dois tratamentos de adubação e duas datas de coleta.

\begin{tabular}{|c|c|c|c|c|c|c|}
\hline \multirow{2}{*}{ Tratamentos } & \multicolumn{2}{|c|}{----------------Densidades---------------- } & \multirow{2}{*}{$\begin{array}{l}\text { Porosidade } \\
\text { Total }\end{array}$} & \multirow{2}{*}{ DMPAs } & \multirow{2}{*}{ DMPAu } & \multirow{2}{*}{$\begin{array}{c}\text { DMPAu/DMP } \\
\text { As }\end{array}$} \\
\hline & Partículas & Solo & & & & \\
\hline & \multicolumn{2}{|c|}{ 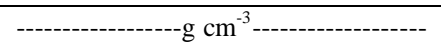 } & \multicolumn{2}{|c|}{ - - } & -------- & 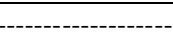 \\
\hline Adubado & $2,64 \mathrm{a}$ & $1,40 \mathrm{~b}$ & $0,470 \mathrm{a}$ & $2,998 \mathrm{a}$ & $0,467 \mathrm{a}$ & 0,156 a \\
\hline Não Adubado & $2,64 \mathrm{a}$ & $1,38 \mathrm{a}$ & $0,477 \mathrm{a}$ & $2,962 \mathrm{a}$ & $0,490 \mathrm{a}$ & $0,165 \mathrm{a}$ \\
\hline SG & $2,64 \mathrm{a}$ & $1,39 \mathrm{a}$ & $0,473 \mathrm{a}$ & 2,925 a & $0,455 \mathrm{a}$ & $0,155 \mathrm{a}$ \\
\hline SD & $2,64 \mathrm{a}$ & $1,40 \mathrm{a}$ & $0,470 \mathrm{a}$ & $3,061 \mathrm{a}$ & $0,486 \mathrm{a}$ & $0,159 \mathrm{a}$ \\
\hline $\mathrm{CC}$ & $2,64 \mathrm{a}$ & $1,38 \mathrm{a}$ & $0,477 \mathrm{a}$ & $2,954 \mathrm{a}$ & 0,495 a & $0,167 \mathrm{a}$ \\
\hline Ano de 1998 & $2,64 \mathrm{a}$ & $1,36 \mathrm{a}$ & $0,485 \mathrm{a}$ & 3,115 a & $0,609 \mathrm{a}$ & $0,196 \mathrm{a}$ \\
\hline Ano de 2004 & $2,64 \mathrm{a}$ & $1,42 \mathrm{~b}$ & $0,462 \mathrm{~b}$ & $2,845 \mathrm{~b}$ & $0,348 \mathrm{~b}$ & $0,122 \mathrm{~b}$ \\
\hline
\end{tabular}

Valores seguidos de mesma letra minúscula na coluna, dentro de cada fator, não diferem estatisticamente $($ Tukey, $\mathrm{P}<0,05)$.

Ciência Rural, v.41, n.9, set, 2011. 
preparo no SPD. A densidade do solo aumentou no tratamento adubado e com o tempo de cultivo. Do mesmo modo, o solo tende a sofrer compactação pelas operações de colheita, adubações, aplicação de defensivos e adensamento natural no cultivo por anos seguidos sob SPD (BERTOLet al., 2000), o que também foi observado por ARATANI et al. (2009), que determinaram aumento na densidade do solo ao final de cinco anos de cultivo com semeadura direta comparativamente ao cultivo convencional em sequeiro.

A porosidade total do solo também não foi influenciada pela adubação e pelos sistemas de manejo (Tabela 1), o que está relacionado ao fato da variação na densidade do solo ter sido mínima, uma vez que a porosidade é calculada a partir da densidade do solo e das partículas. CARNEIRO et al. (2009) observaram que, embora os sistemas de manejo sob semeadura direta e cultivo convencional tenham modificado a densidade do solo, não houve variação na sua porosidade total. Por outro lado, observou-se que a porosidade total foi influenciada pelos anos de cultivo, sendo maior no início do experimento, o que pode ser explicado pela variação na densidade, bem como pela reconsolidação natural do solo entre a primeira e a segunda coleta. Com o aumento da densidade do solo no sétimo ano, a porosidade diminuiu. Por outro lado, após cinco anos de cultivo em diferentes sistemas de manejo, ARATANI et al. (2009) não observaram alteração na porosidade total do solo.

Tanto a adubação como os sistemas de manejo do solo não promoveram mudanças nos resultados do DMPAs, DMPAu e na relação DMPAu/ DMPAs (Tabela 1). Provavelmente, o aporte de resíduos na superfície, a ausência de revolvimento do solo e o tempo de avaliação não foram suficientes para promover diferenças entre a semeadura direta e o cultivo convencional nessas condições edafoclimáticas. Esses resultados são diferentes dos obtidos por de SILVA et al. (2000), que observaram maior agregação na semeadura direta em comparação ao cultivo convencional com capinas, associando esse fato ao aumento do teor de matéria orgânica nesse sistema de cultivo.

O solo estudado apresenta uma fragilidade natural dos seus agregados, sendo devido ao fato de o solo ser constituído predominantemente da fração areia. CUNHA et al. (2001) informam que a predominância da fração areia na textura do solo é um indicativo da fragilidade do sistema como um todo. A utilização desse solo nesses anos de cultivo, em sistemas agrícolas com culturas anuais, agravou ainda mais esta situação, promovendo uma diminuição no diâmetro e na estabilidade dos agregados.
Com os anos de cultivo, ocorreu maior aporte de restos culturais na superfície em todos os sistemas de manejo (Figura 1A), de modo que, a partir do quarto ano, a cobertura se situou próxima dos $100 \%$ logo após a colheita do milho nos sistemas SG e SD. O sistema SG apresentou sempre maior percentagem de cobertura que o sistema SD, mas apenas no ano de 2003 a diferença foi significativa, o que pode ser atribuído à fitomassa do guandu, que foi podada, picada e depositada na superfície do solo.

A produtividade do milho (Figura 1B) é influenciada pela adubação mineral com N, P e K, independente dos anos e sistemas de manejo do solo. O uso de fertilizantes é uma prática que favorece o aumento da produtividade (SILVA et al., 2006; SILVA \& SILVA, 2008), mas seu efeito depende da precipitação pluvial durante o desenvolvimento da cultura, por se tratar de agricultura de sequeiro. A produtividade variou entre os anos de cultivo em função da variação na precipitação pluvial, sendo que menor efeito dos fertilizantes ocorreu nos anos de 1998, 2001 e 2002, que foram os mais secos, e o maior efeito nos anos de 2000, 2003 e 2004, quando ocorreram precipitações pluviais maiores. Por outro lado, a produtividade do milho foi menos variável nos tratamentos sem adubação, parecendo não ser influenciada pela disponibilidade hídrica durante o ciclo do milho. A produtividade média do milho pode ser considerada boa, pois, de acordo com GADIOLI et al. (2000), o milho normalmente apresenta rendimentos inferiores a $3.000 \mathrm{~kg} \mathrm{ha}^{-1}$ quando cultivado em agricultura de sequeiro na região.

A prática da adubação mineral na agricultura dependente das chuvas apresenta riscos, uma vez que envolve custos que na maioria das vezes não é revertido em produtividade, acarretando prejuízo financeiro (SILVA et al., 2009). Isso porque as chuvas no Nordeste têm uma variação intensa no tempo e no espaço, ficando difícil identificar qual ano, ou em que período dele, deve-se utilizar a adubação mineral, bem como se esta traria retorno econômico ou não. Isso é particularmente importante para a cultura do milho, que se caracteriza por consumir bastante água, necessitando, em média, de $573 \mathrm{~mm}$ de água para completar seu ciclo vegetativo sem deficiência hídrica (FORNASIERI FILHO, 1992).

Na região onde foi conduzido o experimento, ocorre elevada variabilidade local e temporal das chuvas, mas a média anual é de aproximadamente $1.100 \mathrm{~mm}$. Porém, no período de estudo, as precipitações pluviais totais anuais variaram de $530 \mathrm{~mm}$ do ano de menor precipitação até $2.027 \mathrm{~mm}$ no ano de maior precipitação. Além disso, a produtividade nem sempre foi maior no ano com maior pluviosidade, visto que a 


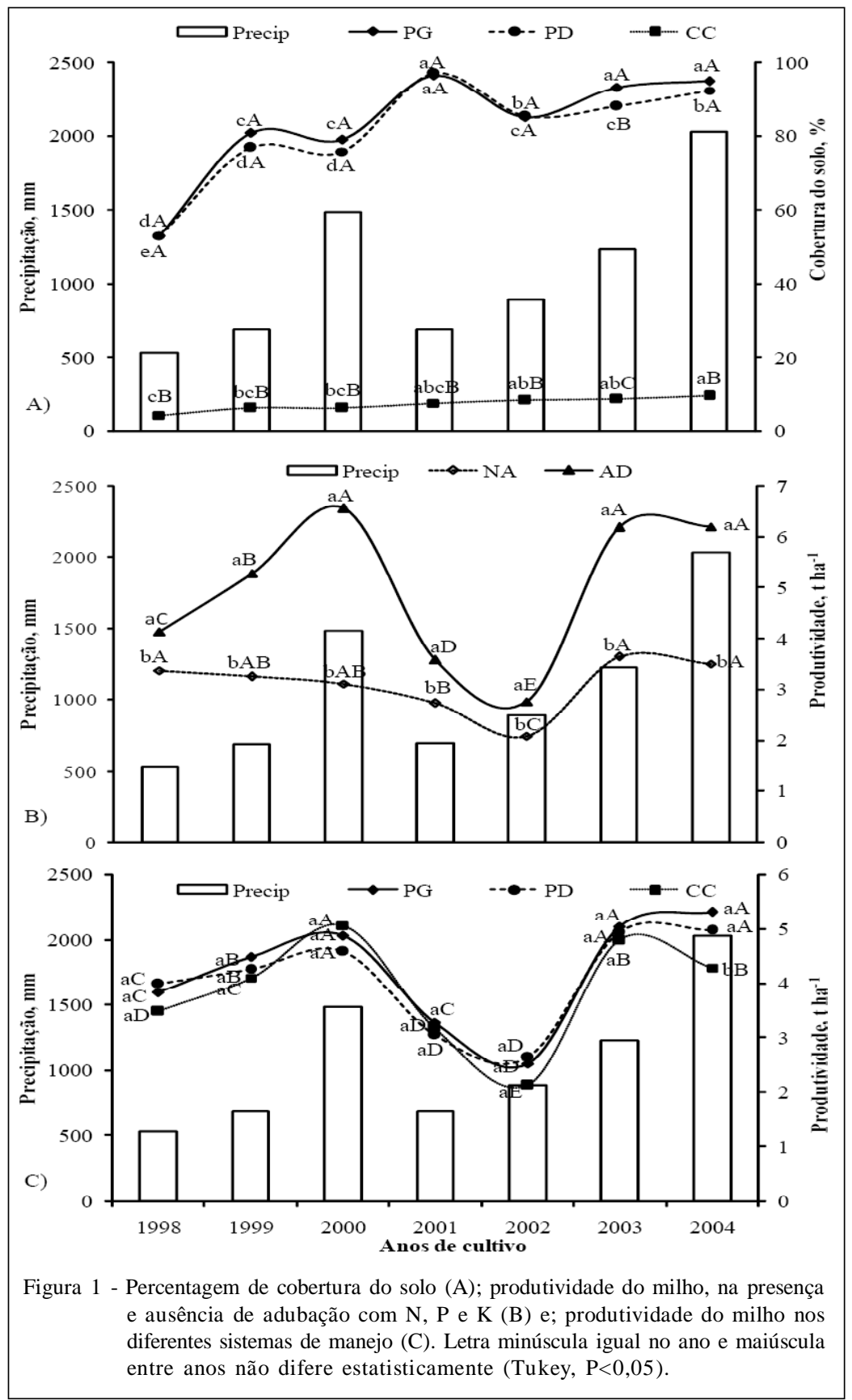

precipitação nem sempre ocorreu na fase fenológica, na qual a cultura necessita de maior disponibilidade de água.

A produtividade de milho nos sistemas de manejo estudados não diferiu nos primeiros seis anos de cultivo (Figura 1C). Apenas no sétimo ano o sistema CC apresentou produtividade menor que a dos sistemas SG e SD, o que ocorreu provavelmente devido aos benefícios acumulados ao solo da manutenção dos resíduos das culturas na lavoura no sistema de semeadura direta, bem como por proporcionar menor erosão, menor temperatura e maior umidade na camada superficial do solo (VIEIRA et al., 1991; SCHICK et al., 2000). Não houve diferença na produtividade do milho entre os sistemas de semeadura direta (SG e SD), após sete anos de cultivo, embora WEBER \& MIELNICZUK (2009) afirmem que o cultivo intercalar de guandu adiciona $\mathrm{N}$ ao sistema de produção.

A produtividade da cultura do milho nos sistemas de manejo SG, SD e CC foi afetada principalmente pelo regime pluvial, sendo a maior 
variabilidade observada no sistema CC, que, a partir do quinto ano de cultivo, passou a ser menor que nos sistemas SG e SD, embora a diferença só tenha sido significativa no sétimo ano de cultivo. Isso ocorre provavelmente porque a cultura cultivada sob CC está mais sujeita aos efeitos das variações climáticas como umidade e temperatura (VIEIRA et al., 1991; SILVA et al., 2006), visto que a proteção por cobertura vegetal era mínima.

\section{CONCLUSÃO}

É possível acumular fitomassa na superfície do solo manejado sob sistema de plantio direto na região Nordeste, embora esse acúmulo seja muito lento. O principal regulador do acúmulo de fitomassa, da produtividade do milho, da eficiência dos fertilizantes minerais e dos sistemas de manejo adotados é a precipitação pluvial, sendo que a produtividade do milho foi superior na semeadura direta em relação ao cultivo convencional no sétimo ano de cultivo.

\section{REFERÊNCIAS}

AMARAL, A.J. et al. Redução da erosão hídrica em três sistemas de manejo do solo em um Cambissolo Húmico da região do Planalto Sul-Catariense. Revista Brasileira de Ciência do Solo, v.32, n.5, p.2145-2155, 2008. Disponível em: <http:// www.scielo.br/pdf/rbcs/v32n5/35.pdf >. Acesso em: 4 de jun. 2011. doi: 10.1590/S0100-06832008000500035.

ANDRIOLI, I. Plantas de cobertura em pré-safra à cultura do milho em plantio direto, na região de Jaboticabal-SP. 2004. 78f. Tese (Livre Docência) - Programa de Pós-graduação em Agronomia, Universidade Estadual Paulista, SP.

ARATANI, R.G. et al. Qualidade física de um Latossolo Vermelho Acriférrico sob diferentes sistemas de uso e manejo. Revista Brasileira de Ciência do Solo, v.33, v.3, p.677687, 2009. Disponível em: <http://www.scielo.br/pdf/rbcs/ v33n3/v33n3a20.pdf $>$. Acesso em: 4 de jun. 2011. doi: 10.1590/S0100-06832009000300020.

BAYER, C.; MIELNICZUK, J. Dinâmica e função da matéria orgânica. In: SANTOS, G.A. et al. (Eds.). Fundamentos da matéria orgânica do solo: ecossistemas tropicais e subtropicais. Porto Alegre: Metrópole, 2008. p.7-18.

BAYER, C. et al. Efeito de sistemas de preparo e de cultura na dinâmica da matéria orgânica e na mitigação das emissões de CO. Revista Brasileira de Ciência do Solo, v.24, n.3, p.599607,2000

BERTOL, I. et al. Propriedades físicas de um Cambissolo húmico álico afetados pelo manejo do solo. Ciência Rural, v.30, n.1, p.91-95, 2000. Disponível em: <http://www.scielo.br/pdf/cr/ v30n1/a15v30n1.pdf>. Acesso em: 4 de jun. 2011.

BRASIL. Ministério da Agricultura. Escritório de Pesquisas e Experimentação. Equipe de Pedologia e Fertilidade do Solo. I. Levantamento exploratório-reconhecimento de solos do
Estado da Paraíba. II. Interpretação para uso agrícola dos solos do Estado da Paraíba. Rio de Janeiro, 1972. 683p. (Boletim Técnico, 15; SUDENE. Série Pedologia, 8).

CARNEIRO, M.A.C. et al. Atributos físicos, químicos e biológicos de um solo sob diferentes sistemas de uso e manejo. Revista Brasileira de Ciência do Solo, v.33, n.1, p.147157, 2009. Disponível em: <http://www.scielo.br/pdf/rbcs/ v33n1/16.pdf $>$. Acesso em: 4 de jun. 2011. doi: 10.1590/ S0100-06832009000100016.

CARPENEDO, V.; MIELNICZUK, J. Estado de agregação e qualidade de agregados de latossolos roxos, submetidos a diferentes sistemas de manejo. Revista Brasileira de Ciência do Solo, v.14, n.1, p.99-105, 1990.

CUNHA, T.J.F. et al. Impacto do manejo convencional sobre propriedades físicas e substâncias húmicas de solos sob cerrado. Ciência Rural, v.31, n.1, p.27-36, 2001. Disponível em: <http://www.scielo.br/pdf/cr/v31n1/a05v31n1.pdf〉. Acesso em: 4 de jun. 2011.

EMPRESA BRASILEIRA DE PESQUISA AGROPECUÁRIAEMBRAPA. Centro Nacional de Pesquisa de solos. Manual de métodos de análises de solo. Rio de Janeiro, 1997. 212p.

EMPRESA BRASILEIRA DE PESQUISA AGROPECUÁRIAEMBRAPA. Sistema brasileiro de classificação de solos. 2.ed. Brasília: EMBRAPA Produção de informação; Rio de Janeiro, EMBRAPA Solos, 2006. 306p.

FORNASIERI FILHO, D. A cultura do milho. JaboticabalSP: FUNEP, 1992. 273p.il.

FRAGA, V. da S. Mudanças na matéria orgânica (C, N e P) de solos sob agricultura de subsistência. 2002. 76f. Tese (Doutorado em Solos) - Programa de Pós-graduação em Tecnologias Energéticas e Nucleares, Universidade Federal de Pernambuco, Recife, PE.

GADIOLI, J. L. et al. Temperatura do ar, rendimento de grãos de milho e caracterização fenológica associada à soma calórica. Scientia Agrícola, v.57, n.3, p.377-383, 2000. Disponível em: 〈http://www.scielo.br/pdf/sa/v57n3/2663.pdf〉. Acesso em: 4 de jun. 2011.

NUNES, H.V. Plantio direto e decomposição de restos culturais em diferentes sistemas de cultivos. 2006. $86 \mathrm{f}$. Tese (Doutorado em Agronomia) - Programa de Pósgraduação em Agronomia, Universidade Federal da Paraíba, PB. Disponível em: <http://www.cca.ufpb.br/ppga/pdf/doutorado/Helberdr06.pdf>. Acesso em: 4 de jun. 2011.

NUNES, H.V. et al. Influência de diferentes sistemas de culturas e adubações sobre componentes de rendimento de grãos de milho cultivado em plantio direto. In: REUNIÃO BRASILEIRA DE MANEJO E CONSERVAÇÃO DO SOLO E DA ÁGUA, 15., 2004, Santa Maria, RS. Anais... Santa Maria: RBMCSA, 2004. (CD - ROM)

SAMPAIO, E.V.S.B. et al. Fertilidade dos solos do semi-árido. In: PEREIRA, J.R.; FARIA, C.M.B. (Eds.). Fertilizantes: insumo básico para a agricultura e combate à fome. Petrolina: Embrapa/CPATSA/SBCS, 1995. p. 51-69. 
SCHICK, J. et al. Erosão hídrica em Cambissolo Húmico Alumínico submetido a diferentes sistemas de preparo e cultivo do solo: I Perdas de solo e água. Revista Brasileira de Ciência do Solo, v.24, n.2, p.427-436, 2000

SILVA, A.S. Propriedades físicas e químicas do solo, sistema radicular e produtividade do milho sob diferentes sistemas de manejo na microrregião de Guarabira-PB. 2002. 80f. Dissertação (Mestrado em Solos) - Programa de Pós-graduação em Manejo e Conservação do solo e Água, Universidade Federal da Paraíba, PB.

SILVA, A.S.; SILVA, I.F. da. Efeitos da temperatura e umidade do solo na produtividade do milho. Cadernos Temáticos. In:

Riqueza e tecnologia Brasileira. Brasília: SETEC, 2008. N.19. Disponível em: <http://portaldoprofessor.mec.gov.br/ storage/materiais/0000013556.pdf>. Acesso em: 4 de jun. 2011.

SILVA, A.S. et al. Avaliação dos custos da adubação com N-P$\mathrm{K}$ na cultura do milho em agricultura de sequeiro. In: CONGRESSO BRASILEIRO DE CIÊNCIA DO SOLO - O SOLO E A PRODUÇÃO DE BIOENERGIA: PERSPECTIVAS E DESAFIOS, 32., 2009, Fortaleza, CE. Anais... Fortaleza: SBCS - CE, 2009. (CD ROM).

SILVA, I.F.; MIELNICZUK, J. Sistemas de cultivo e características do solo afetando a estabilidade de agregados. Revista Brasileira de Ciência do Solo, v.22, n.2, p.311317, 1997.

SILVA, E.C. et al. Manejo de nitrogênio no milho sob plantio direto com diferentes plantas de cobertura, em Latossolo Vermelho. Pesquisa Agropecuária Brasileira, v.41, n.3, p.477-486, 2006. Disponível em: <http://www.scielo.br/pdf/ pab/v41n3/29120.pdf>. Acesso em: 4 de jun. 2011. doi: 10.1590/S0100-204X2006000300015.
SILVA, M.L.N. et al. Sistemas de manejo e qualidade estrutural de Latossolo roxo. Pesquisa Agropecuária Brasileira, v.35, n.12, p.2485-2492, 2000. Disponível em: <http://www.scielo.br/ pdf/pab/v35n12/a19v3512.pdf>. Acesso em: 4 de jun. 2011.

SILVA NETO, L.F. Influência do plantio direto e da cobertura vegetal sobre os atributos físicos e matéria orgânica do solo e produtividade do milho. 2003. 41f. Monografia (Curso de Agronomia) - Centro de Ciências Agrárias, Universidade Federal da Paraíba, PB.

SLONEKER, L.L.; MOLDENHAUER, W.C. Measuring the amounts of crop residue remaining after tillage. Journal of Soil and Water Conservation, v.32, p.231-236, 1977.

TISDALL, J.M. et al. The stability of soil aggregates as affected by organic materials microbial activity and physical dsireption. Australian Journal of Soil research. v.16, p.9-17, 1978.

TORRES, J.L.R. Estudo de plantas de cobertura na rotação milho-soja em sistema de plantio direto no cerrado, na região de Uberaba-MG. 2003. 108f. Tese (Doutorado em Agronomia) - Programa de Pós-graduação em Agronomia, Universidade Estadual Paulista, SP.

VIEIRA, S.R. et al. Umidade e temperatura da camada superficial do solo em função da cobertura morta por resteva de soja em plantio direto. Revista Brasileira de Ciência do Solo, v.15, n.2, p.219-224, 1991.

WEBER, M.A.; MIELNICZUK, J. Estoque e disponibilidade de nitrogênio no solo em experimento de longa duração. Revista Brasileira de Ciência do Solo, v.33, n.2, p.429-437, 2009. Disponível em: <http://www.scielo.br/pdf/rbcs/v33n2/20.pdf>. Acesso em: 4 de jun. 2011. doi: 10.1590/S0100-068320090 00200020 . 